\title{
Implementation of the Lawrence Livermore National Laboratory Elementary Science Study of Nature (LESSON) in North Alabama Elementary and Middle Schools
}

Project \# 5190005

Final Report Covering the Period

July 1984 - June 1989

Submitted by:

Saundra Y. McGuire

Department of Chemistry Alabama A \& M University

Normal, Alabama 35762

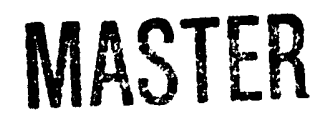
DISTAIBUTION OF THIS DOCUMENT IS UNLIMITED

Prepared for the Lawrence Livermore National Laboratory

Livermore, California 


\section{DISCLAIMER}

Work performed under the auspices of the U.S. Department of Energy by Lawrence Livermore National Laboratory under contract number $\mathbf{W}-7405-E N G-48$.

This document was prepared as an account of work sponsored by an agency of the United States Government. Neither the United States Government nor the University of California nor any of their employees, makes any warranty, express or implied. or assumes any legal liability or responsibility for the accuracy, completeness, or usefulness of any information, apparatus, product, or process discloser, or represents that its use would not infringe privately owned rights. Reference herein to any specific commercial products, process, or service by trade name, trademark, manufacturer, or otherwise, does not necessarily constitute or imply its endorsement, recommendation, or favoring by the United States Government or the University of California. The views and opinions of authors expressed herein do not necessarily state or reflect those of the United States Government or the University of California, and shall not be used for advertising or product endorsement purposes. 


\title{
Implementation of the Lawrence Livermore National Laboratory Elementary Science Study of Nature (LESSON) in North Alabama Elementary and Middle Schools
}

\author{
introduction
}

The Alabama A \& M University - Lawrence Livermore National Laboratory (LLNL) Elementary Science Study of Nature (ALALESSON) was designed to improve elementary and middle school science in North Alabama by involving teachers in a two-week summer workshop as well as other follow-up activities. The purpose of the activities was to increase the science knowledge of the teachers and to provide them with materials and activities for hands-on science lessons. The summer workshops, conducted during the summers of 1984 and 1985, provided instruction and materials for activities in the areas of biology, chemistry, physics, and electricity and magnetism. The materials included equipment whose total value was over $\$ 400.00$. Additionally, a manual containing 43 lessons which included background information, experiments and activities for classroom and home use was provided to each teacher. During the course of the project activities, the teachers interacted with fourteen scientists from Alabama A \& M University, four scientists from Lawrence Livermore National Laboratory, eight staff members from the NASA Marshall Space Flight Center, three staff members from the University of Alabama at Huntsville Johnson Environmental Education Center, two North Alabama teachers who served as presenters, and one NASA Teacher in Space Finalist, Kathleen Beres. This report will thus detail activities during the period July 1984 - June 1989.

\section{Teacher/Counselor/Administrator Training Project Summary}

\section{Administrative}

A. Participant Recruitment and Selection

Project ALALESSON sought teacher participants from elementary and middle school grades (targeting grades 3 - 8) for participation in the program. These grades were targeted because the science material content of the program was most congruent with material appearing in the science curriculum of those grades. However, applicants from other grades within the schools were not eliminated in the selection process because of the changes in grade assignments that often occur in the school system. (For example, a teacher may teach kindergarten one year and fourth grade the next.) Also, high school teachers who expressed a strong interest in the program were not eliminated because much of the content is applicable to high school physical sciences courses as well as elementary and middle school.

The number of workshop participants selected and agreeing to participate was thirty-two in 1984 and twenty-eight in 1985. Of the sixty total participants, forty-one were elementary teachers, seventeen were middleschool teachers, and two were high school teachers. Two of the teachers were 
Special Eciscation teachers --one for gifted education, and one for slow learners. All were currently teaching or planning to teach in North Alabama.

A number of different mechanisms ware used to attract teachers. Notification of the workshop was sent to all North Alabama inservice-education coordinators, all principals, and selected elementary and middle school teachers throughout the four county, ten school-district region served by the project. (The selected teachers were those who had previously participated in a workshop sponsored by the Alabama A \& M -UAH Regional Inservice Education Center. In addition, an article about the workshop appeared in the local newspapers soliciting participants. One of the most effective recruiting techniques was the publicity provided by former participants in the two-day workshop conducted in the Huntsville City Schools during the spring of 1984 . Teachers told other teachers in their schools about the workshop and encouraged them to attend. Finally, the Project Director contacted some teachers directly who had expressed an interest in and a need for participating in a science workshop. The least effective mechanism seemed to be the communications sent to principals and system inservice coordinators. There was a delay in getting the information to the teachers, and some participants reported that their principal provided the information only to those teachers that he or she personally wanted to participate in workshop activities. Thus, the majority of teachers at the school would not be aware of the workshop activities. The newspaper article and the direct contact with teachers were the most effective recruitment mechanisms.

Based on experience with this project, the preferred strategy for recruiting participants is to contact teachers directly via presentations at local inservice activities and direct mail contact. However, one problem with the selection of participants was that teachers would indicate that they were definitely coming to the workshop, but then not show up when the workshop actually started. It was necessary to write to teachers asking them to please let us know if they were not going to be able to participate so that others could use their spaces. This effort was marginally successful, but during the second workshop session, attendance was affected by the cancelling out at the last minute of several of the planned participants. It is nearly impossible for other teachers (from an aiternates list, for example) to attend a two week workshop on very short notice. Those contacted either had problems arranging for child care or had made other plans for at least part of the two week period.

\section{B. Scheduling}

A workshop that provides teachers with instruction in the areas of biology, physics, chemistry, and electricity and magnetism, as well as allowing them to individually participate in a variety of hands-on activities requires approximately 35 - 40 hours of on-site instruction to teachers. A two-week block of time with four hours of instruction each day was used with Project 
ALALESSON because teachers had indicated that a one week block with eight hours of instruction per day forced them to cram too much information, and that committing more than two weeks of time to such a project was unfeasible for teachers who have only two months away from regular classroom duties. One common problem experienced by workshops that are longer than two to three days in length is absenteeism. However, the ALALESSON participants were informed that they were expected to participate each day unless emergencies arose that made it impossible to attend. Most participants attended all ten days of the workshop.

Since the workshop assumed no prior existing science knowledge, the sequencing of workshop activities was designed to start teachers off with the familiar--biology. Physics was offered next to show them how exciting physics can be while the interest level in workshop activities was still at a peak, and their fear of physics would not overly dampen their enthusiasm. The electricity and magnetism activities were presented after they had been exposed to some physics. Finally, they were dazzled by the chemistry experiments that involved everyday materials readily available to them and their students. This sequence worked very well.

Since the project was designed to use readily available, low-cost materials, most of the materials were available and ordered in time to be provided to the participants when appropriate. Packaging the materials in the form to be given to the teachers was the most logistically taxing part of the project, but was successfully accomplished by using assistants from the Department of Chemistry at Alabama A \& M University. The set of materials for each of the four units was boxed in a different "kit" and distributed to the teachers at the beginning of the appropriate unit. Thus, at the conclusion of the workshop the teachers had four sturdy boxes--each containing materials with which to do activities in biology, chemistry, physics, or electricity and magnetism. Additionally, teachers were provided with a list of everyday items that can be used to teach science concepts.

\section{Facilities}

The workshop activities were held in one of the biology laboratories of Carter Hall, the science building at Alabama A \& M University. The size of the room was quite adequate as were the facilities--running water, gas and electrical outlets, and a projection screen. However, the participants in the first workshop complained (justifiably) that the temperature of the room was uncomfortably warm and the air-conditioner extremely loud. In the subsequent summer this problem was corrected.

The workshop accessibility to participants was excellent. There were no residential provisions made as all participants resided within commuting 
distance of the workshop activities. Transportation was provided by the participants themselves. No per diem or mileage allowance was provided since the participants were getting the workshop instruction and materials free of charge. The only incentive for attending the workshop was the $\$ 400.00$ worth of materials that teachers knew they would be receiving throughout the course of the two weeks.

The cooperation between members of the departments of chemistry, biology, physics, and electrical engineering technology at Alabama $A \& M$, as well as representatives from the Lawrence Livermore National Laboratory, NASA Marshall Space Flight Center and the Johnson Environmental Center at the University of Alabama at Huntsville was crucial to the success of the project. The presence of so many scientists on campus and making presentations to participating teachers was a great advantage for the program. Additionally, the teachers were provided with resource persons whom they called upon during the school year to speak to their classes.

\section{Program Staff and Administrators}

The project was administered solely by the Project Director, Saundra Y. McGuire. Secretarial assistance was provided by the Department of Chemistry and the Alabama A \& M -UAH Regional Inservice Education Center. The teaching staff of the Program was recruited from the science departments of Alabama A \& M University, Lawrence Livermore National Laboratory, the NASA Marshall Space Flight Center, and the University of Alabama, Huntsville Johnson Environmental Center. The members of the teaching staff were from a variety of disciplines, in keeping with the nature of the workshop. A total of twenty-seven scientists and/or administrators worked with the teachers. Sixteen of these were from Alabama A \& M, four from Lawrence Livermore National Laboratory, eight from the Marshall Space Flight Center, and three from the UAH Johnson Environmental Education Center.

The training for the teaching staff included an orientation session on the nature of the program and the characteristics of the teachers who would be participating in the project. The emphasis in the orientation sesision was on the "hands-on" aspects of the workshop sessions. Each instructor was admonished to talk for only 15 - 20 minutes before beginning the experimental activities so as not to frustrate the teachers. Although most of the teaching staff were faculty members, most had never taught a course to elementary teachers. After teaching, however, most indicated that they had enjoyed working with the teachers. All expressed a desire to work with teachers again in the future. The teachers rated most of the presenters very highly on their evaluation instruments, but some were viewed as being either too technical in the presentation or too "condescending" to the teachers. Follow-up sessions with these instructors helped them to improve for future sessions. 


\section{E. Collaboration}

As stated earlier, the collaborative effort during the workshop presentation was primarily between Alabama A \& $M$ University, Lawrence Livermore National Laboratory, the NASA Marshall Space Flight Center, the A \& $M$ - UAH Regional Inservice Education Center, and the Johnson Environmental Center. Additionally, the Lawrence Livermore National Laboratory, which developed the curriculum materials used in the program, participated after the initial two years of the effort by co-sponsoring the national conferences held in January of 1987 and 1988 to publicize the workshop and project activities to faculty members from other Historically Black Colleges and Universities (HBCU's) around the nation.

Some local organizations also participated in the collaboration. The local hospitals donated old $x$-rays of human chest cavities and other areas (minus the patient identification information), local bottlers donated empty plastic 2-liter bottles, and Alabama $A$ \& $M$ donated bricks.

With regard to services to other educator groups, the Project Director made a presentation to participants in the Summer Training Institute at the University of Buffalo in 1987. The Institute was conducted for teachers of students in the minority student programs sponsored by the Center for Urban Affairs at the University. There were approximately 65 teachers in attendance at the session. The day after the presentation to teachers the Project Director made a presentation as part of a panel to approximately 125 minority students participating in the summer programs at the University. The visit was arranged by Mr. Clyde Foster, who was then Director of the Office of Equal Opportunity at the Marshall Space Flight Center. Other presentations inciuded a paper presented at the annual meeting of the National Organization for the Professional Advancement of Black Chemists and Chemical Engineers (NOBCChE) held in San Francisco, CA in April 1987. Additionally, a presentation was made in October, 1988 at the First Annual Symposium for Black Americans in Science, Engineering, and Technology, held at the NASA Johnson Space Center in Houston. Presentations were also made at the annual NASA/HBCU Conference held in 1986 and 1987 in Atlanta, Georgia and in April 1989 in Huntsville, Alabama; to the PTA of the Academy for Academics and Arts Elementary and Middle School in Huntsville; and a teacher workshop held in April 1988 and April 1989 in Hampton, Virginia.

In July of 1984 the Project Director attended the LESSON workshop conducted by LLNL scientists in Oakland, California. It was during this workshop that she developed a clear understanding of the content ad philosophy of LESSON workshops. In addition, she interviewed Manuel Perry, the LLNL scientist who first proposed that the laboratory become involved with the schools in the San Francisco Bay area in an effort to increase the number of potential employees from the local area. This provided the Project Director 
with a sense of the history of the program and the goals and objectives it strives to meet.

The first ALALESSON workshop was conducted in August of 1984 at Alabama A \& $M$ University. The kit materials for this workshop were packaged and shipped to Alabama $A \& M$ by LLNL, and the workshop presenters were scientists from LLNL and Alabama A \& M. The materials for the 1985 workshop were purchased and packaged by Alabama $A \& M$ with funds from the grant. It was also during the 1985 workshop that scientists from the Marshall Space Flight Center and the Johnson Center for Environmental Education became involved with the project.

The elementary and middle schools of the participating teachers were not intimately involved in the planning of this project. However, several participating teachers were referred to the program by their principals. No facilities were provided by the schools, but the participating teachers actually became part of the teaching staff on the final day when they made presentations to their fellow participants.

Other than the presentations by teachers, all workshop activities were planned by faculty from Alabama A \& M University and scientists from Lawrence Livermore National Laboratory and the NASA Marshall Space Flight Center. The University provided the classroom facilities and some equipment (such as plant models) for use in the workshop.

\section{F. Curriculum and Materials Planning}

The curriculum for this project was taken from the Lawrence Livermore National Laboratory's Elementary Science Study of Nature (Project LESSON). The four basic science areas of physics, chemistry, biology, and electricity and magnetism were the topics of study. These topics are included in the workshop curriculum because these are the topics that are covered in elementary and middle school science. The curriculum materials stress the contributions of minority scientists; use low-cost, easily accessible materials; and are exciting to students and teachers. Trius, they are especially useful to this population of teachers.

Other workshop materials were taken from other sources that stress experiential science learning activities. The "Sounds of Science" materials developed by Dr. Carole Hardeman at the University of Oklahoma are particularly effective in showing middle school students successful minority, female, and handicapped scientists at work. Some of these materials were used during the workshop. Additionally, books with science experiments for children were constantly used as reference materials. 


\section{G. Participant/Project Monitoring and Evaluation}

The project activities were monitored daily by the Project Director, and informal teacher feedback sessions took place throughout the two week sessions. Additionally, a written evaluation form was completed by participants at the conclusion of each workshop. They indicated strengths and weaknesses of the workshop activities. The oral and written evaluations were quite helpful in making minor modifications in the workshop activities. However, since most of the comments were overwhelmingly positive, the teachers indicated that they say little need for changes.

The long-term evaluation plans were not nearly as successful as the shortterm evaluations. The Project Director met with little success in obtaining responses to questionnaires distributed to teachers. Follow-up telephone calls also did not yield the promised completed questionnaires. More pressure should have been placed on the teachers to get this information submitted, but this was not applied in enough instances. Hence, the only long-term evaluation data is in the form of verbal reports from teachers (and principals) who continue to indicate that the workshop has had a tremendous impact on the science activities of their students (and teachers). In retrospect, it would probably have been useful to obtain signed contracts from teachers who participated, as well as kept in closer contact with them after the workshop activities were over.

The pre-test and post-test data indicate that teachers do make significant gains in science knowledge during the workshop. Follow-up post-testing on one sample of teachers demonstrated that there is no significant loss of these gains up to six-months after the workshop has ended.

\section{H. Fiscal and Development Activities}

The financial incentives for project participants were not direct in the sense that teachers did not receive a stipend or a travel allowance. However, teachers did receive approximately $\$ 400.00$ worth of science equipment to use in their classrooms, and this was a great incentive for themi to participate.

Activities to generate non-LLNL support included a presentation to the Parent Teacher Association of one of the local schools, contacting the Army Missile Command's Office of University Relations, beginning a collaboration with the Marshall Space Flight Center, and utilizing State funds provided by the Regional Inservice Education Center. The resources provided by these agencies included loan of personnel, financial assistance to conduct the national conference, and assistance with the publicity activities of the workshop. Additionally, future workshop activities were included for funding in a 1988 proposal to the National Science Foundation for a Minority Resource Center of Excellence at Alabama A \& M University. This proposal has been funded, and future workshop activities will not require funding from LLNL. Hence, the 
Project goal to continue the activities after LLNL funding ceased has been realized.

\section{Service Delivery}

The workshop activities were conducted almost entirely as planned. However, post-workshop activities deviated somewhat from the plan. First, the classroom visitations were more difficult to schedule than had been anticipated. Most of the teachers were hesitant to have an observer in the classroom, and the Project Director was not insistent enough that the visitations be made.

However, the Project Director did visit the classrooms of approximately ten of the participants, and the responses of the students to the materials were quite enthusiastic.

\section{A. Diagnustic}

As for diagnostic testing of individual participants, a pre-post test of cognitive science knowledge was administered. No standardized tests were administered because it was necessary that the testir.g instrument reflect the special characteristics of the instruction provided by the Project.

B. Instructional

The formal instructional process included approximately four hours of instruction per day. The four hour period was divided into three or four approximately equal blocks of time to study three or four lessons within a given subject area. As many as three or four different scientists would present information to the teachers on a particular day. The format was particularly effective in keeping the material interesting at all times. Mot of the time was spent with the teachers actually doing science rather than listening to persons talk about science. The cooperation and comraderie that developed among the participants was excellent. They did not appear to be at all inhibited from fully participating in any of the activities and helped each other considerably.

\section{Counseling/Advising}

There was no explicit counseling component to this project. However, the participants were given information on science careers and shown resource materials (e.g. "Sounds of Science") that were designed to motivate students to pursue technical careers. They were also given information on the scientific manpower needs of this country and our inevitable inability to meet these needs by the year 2000 if we do not interest more students in pursuing science as a career. The participants were provided with resource materials that would be especially effective in getting minority, female, and physically handicapped students interested in science. 


\section{Other Service Delivery}

Follow-up visits have established that the project participants share the materials and philosophy of Project AL.ALESSON with their peers in their home school. Although they rarely present formal workshops (most teachers are reluctant to do this after a two-week workshop) there is much informal assistance to other teachers in their schools. It is quite common that a teacher will indefinitely "loan" materials that are associated with curriculum topics that she/he does not teach to the appropriate teacher who covers those topics in her/his science classes. For example, a third grade science teacher may loan the materials on surface tension or electrical circuits to the fifth grade teacher who teaches those topics. In this way, one participant may influence the teaching of three or four other teachers in her/his school.

\section{Participant Outcomes}

This project was designed to enable teachers to effectively teach science concepts in an exciting way using a variety of hands-on materials, as well as devise their own hands-on activities based on their individual curricula for use in their classrooms. To this end, the teachers are encouraged to develop one hands-on activity for demonstration to the workshop participants at the end of the workshop. This particular workshop activity was very successful. Each teacher enjoyed sharing with the others, and there were a series of additional activities that each teacher could add to her/his repertoire at the conclusion of the workshop.

Whereas this project did not address the application of math and science concepts to engineering, the project did stress the importance of integrating science throughout the curriculum. Teachers were shown ways in which science activities could be incorporated into the teaching of English, reading, writir.y, social studies, health, and writing. Thus, the instructional skills of the teachers improved in science as well as in other areas as a result of this project.

When the participants left the two-week workshop, they were quite eager to try out the new materials in their classrooms, and appeared motivated to incorporate the workshop philosophy and instructional techniques in their classroom to increase science interest on the part of their students. The few evaluation questionnaires returned further documented this result.

\section{Project Dissemination}

Information concerning the project was disseminated via presentations to the local, regional, and national groups mentioned earlier. A detailed description of the project and activities was published in The Proceedings of the Fourteenth Annual Meeting of the National Organization for the Professional Advancement of 
Black Chemists and Chemical Engineers in 1987. The project description also appeared in the Proceedings of the First Annual Symposium for Black Americans in Science. Engineering and Technology published by CASET, the Center for the Advancement of Science, Engineering, and Technology. In addition, the Project content and philosophy have been discussed in teacher education courses at both Alabama A \& M University and the University of Alabama in Huntsville.

\section{Conclusion}

The Alabama A \& M University - Lawrence Livermore National Laboratory Elementary Science Study of Nature (ALALESSON) successfully completed two summer workshops that were held for thirty-two North Alabama teachers in year one of the project, and for twenty-eight teachers during the second year of the project. Thus a total of sixty (60) teachers and approximately four thousand $(4000)$ students have been impacted by the project to date. In addition funding from LLNL was used to conduct two national conferences for representatives from other HBCU's and to present information about LESSON to local, regional, and national groups. When one considers the mini-workshops conducted by the Project Director and the "teacher cooperation" effect, the numbers accelerate exponentially. Hence, the project has had a significant impact on science teaching in North Alabama schools. Additionally, a variety of LLNL area scientists were involved in presenting information to the teachers and in performing activities with them.

The teaching of science in the classrooms and schools of the teachers participating in Project ALALESSON has been positively affected by ALALESSON activities, and area teachers have indicated that they are looking forward to future workshop activities of this type. In its funding of ALALESSON, LLNL has made a major contribution to the improvement of science education in North Alabama and elsewhere. The continuation of these types of initiatives is imperative if the future scientific and technological needs of the nation are to be met with a well-educated workforce, thus allowing America to maintain its world leadership in this arena. 


\section{Acknowledgements}

The Project Director wishes to express her sincere appreciation to Mrs. Shirley McDavid, Mr. Paul Forte, Mr. Gerald Davis, and Mr. William O.

Raymond and the participating scientists from the Lawrence Livermore National Laboratory; Mr. Clyde Foster, Mr. James Rice, Mr. Robert Walker, Jr., Mr. William Anderson and the participating scientists from the NASA Marshall Space Flight Center; Dr. Annie Wells and the staff of the Regional Inservice Education Center; Mr. Anthony Onyeabo, materials manager for the Project; participating faculty from Alabama A \& M University and the University of Alabama in Huntsville; and all of the teachers who participated so enthusiastically in Project ALALESSON activities. Each one, in his or her own way, jersonally demonstrated a firm belief that

"If it is to be, it is up to me!"

The future of science education in America is brighter because of the efforts of each of them. 

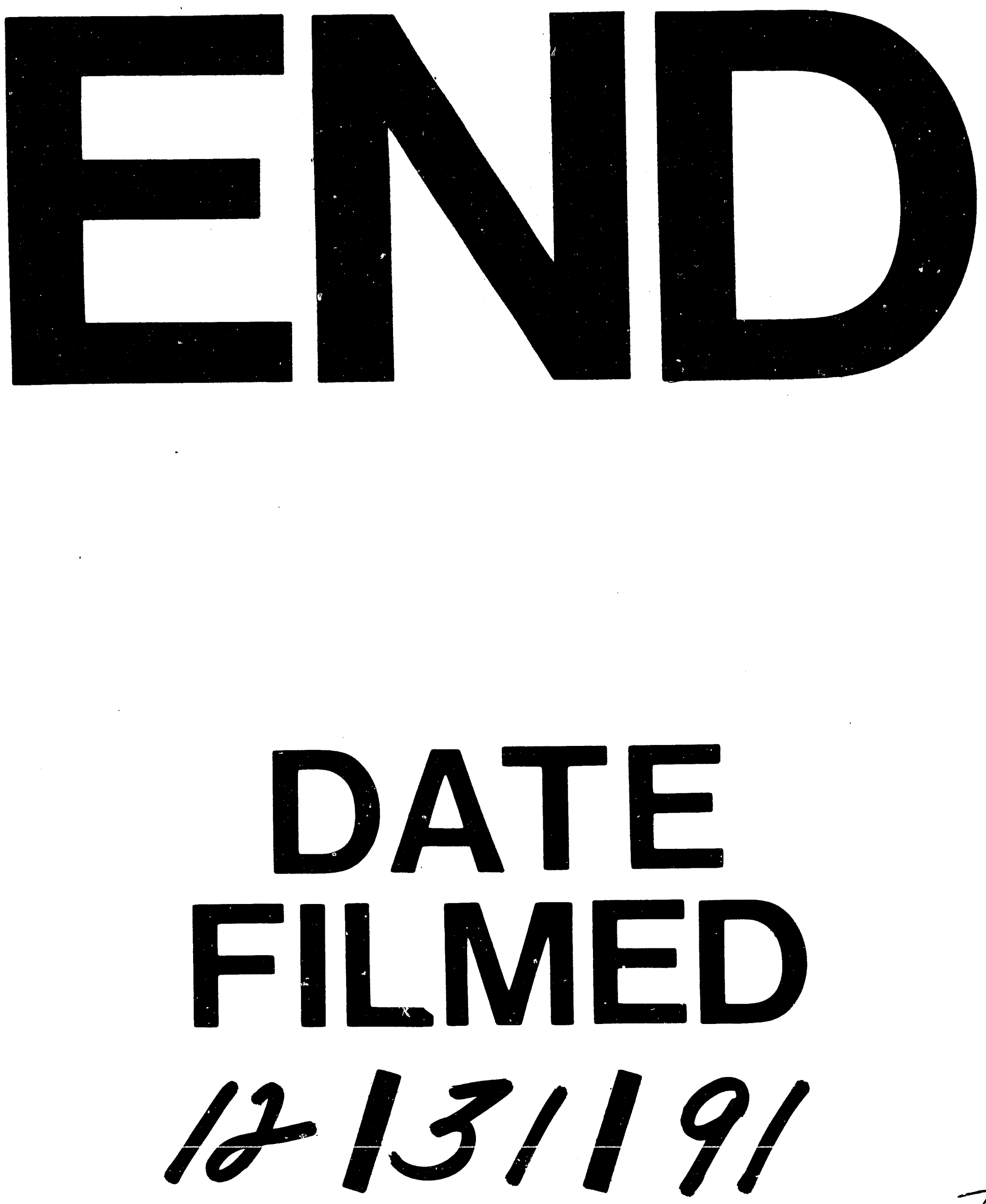
$\overline{\bar{\equiv}}$ 